\title{
Identification and Characterization of Metallothionein-1 and -2 Gene Expression in the Context of $( \pm) 3,4-$ Methylenedioxymethamphetamine-Induced Toxicity to Brain Dopaminergic Neurons
}

\author{
Tao Xie, ${ }^{1}$ Liqiong Tong, ${ }^{1}$ Una D. McCann, ${ }^{2}$ Jie Yuan, ${ }^{1}$ Kevin G. Becker, ${ }^{3}$ Annis 0. Mechan, ${ }^{1}$ Christopher Cheadle, ${ }^{3}$ \\ David M. Donovan, ${ }^{4}$ and George A. Ricaurte ${ }^{1}$ \\ Departments of ${ }^{1}$ Neurology and ${ }^{2}$ Psychiatry and Behavioral Sciences, Johns Hopkins University School of Medicine, Baltimore, Maryland $21224,{ }^{3} \mathrm{cDNA}$ \\ Microarray Unit, Research Resources Branch, Intramural Research Program, National Institute on Aging, National Institutes of Health, Baltimore, \\ Maryland 21224-6825, and ${ }^{4}$ Biotechnology and Germplasm Laboratory, United States Department of Agriculture, Agricultural Research Service, Animal \\ and National Resources Institute, Beltsville, Maryland 20705
}

In mice, the recreational drug $( \pm) 3,4$-methylenedioxymethamphetamine [MDMA ("ecstasy")] produces a selective toxic effect on brain dopamine (DA) neurons. Using cDNA microarray technology in combination with an approach designed to facilitate recognition of relevant changes in gene expression, the present studies sought to identify genes potentially involved in murine MDMA-induced toxicity to DA neurons. Of 15,000 mouse cDNA fragments studied, metallothionein $(M t)-1$ and $M t 2$ emerged as candidate genes possibly involved in MDMA-induced toxicity to DA neurons. Northern blot analysis confirmed the microarray findings and revealed a dynamic upregulation of $M t 1$ and $M t 2$ mRNA in the ventral midbrain within 4-12 hr after MDMA treatment. Western blot analysis showed a similar increase in MT protein levels, with peak times occurring subsequent to increases in mRNA levels. Mt1-2 double knock-out mice were more vulnerable to MDMA-induced toxicity to DA neurons than corresponding wild-type mice. Stimulation of endogenous expression of MT protein with zinc acetate conferred complete protection against MDMA-induced toxicity to DA neurons, and administration of exogenous MT protein afforded partial protection. Collectively, these results indicate that MDMA-induced toxicity to DA neurons is associated with increased $M t 1$ and $M t 2$ gene transcription and translation, possibly as part of a neuroprotective mechanism. The present findings may have therapeutic implications for neuropathological conditions involving DA neurons.

Key words: dopamine; MDMA; neurotoxicity; metallothioneins; amphetamines; microarray

\section{Introduction}

( \pm )3,4-Methylenedioxymethamphetamine (MDMA) is a ringsubstituted amphetamine analog and a popular recreational drug of abuse (Johnston et al., 2004). A large body of data indicates that MDMA is a potent monoaminergic neurotoxin that has the potential to damage brain serotonin (5-HT) and/or dopamine (DA) neurons, depending on the animal species and conditions of administration (Green et al., 2003). In mice, under most conditions, MDMA is a selective toxin toward DA neurons (Logan et al., 1988; O'Callaghan and Miller, 1994; Colado et al., 2001; O'Shea et al., 2001). In particular, after MDMA administration, mice develop long-lasting DA axon terminal damage, whereas DA cell bodies remain intact. Unlike most species, the mouse does not

Received Feb. 5, 2004; revised May 28, 2004; accepted June 2, 2004.

This work was supported by United States Public Health Service Awards DA09487, DA00206, and DA10217 (G.A.R.). We thank William H. Wood III and Diane Teichberg for technical assistance.

Correspondence should be addressed to Dr. George A. Ricaurte, Department of Neurology, Johns Hopkins Medical Institutions, 5501 Hopkins Bayview Circle, Room 5B.71E, Baltimore, MD 21224. E-mail: ricaurte@jhmi.edu. DOI:10.1523/JNEUROSCI.1626-04.2004

Copyright $\odot 2004$ Society for Neuroscience $\quad$ 0270-6474/04/247043-08\$15.00/0 develop 5-HT axon terminal injury after MDMA administration (Green et al., 2003).

Although the mechanisms of MDMA neurotoxicity are not known, development of MDMA-induced toxicity to DA neurons is critically dependent on intact DA transporter (DAT) function. Thus, DAT inhibitors, presumably by preventing access to the DAT, afford complete protection against the toxic effects of MDMA on DA neurons (O'Shea et al., 2001). Interestingly, temperature (ambient and core) can also markedly influence MDMA-induced toxicity to DA neurons (O'Callaghan and Miller, 1994; Colado et al., 2001).

The goal of the present study was to use cDNA microarray methods, in combination with a targeted pharmacological approach, to identify gene expression patterns relevant to early stages of MDMA-induced toxicity to DA neurons. Specifically, by comparing changes in gene expression induced by MDMA in the absence and presence of WIN35,428 (2 $\beta$-carbomethoxy-3 $\beta$-(4fluorophenyl)-tropane, CFT), which blocks MDMA-induced toxicity to DA neurons, we sought to identify changes in gene expression relevant to early phases of the neurotoxic process. To optimize chances of successfully identifying genes directly in- 
volved in murine MDMA neurotoxicity, we used a large, mousederived 15k cDNA microarray (Tanaka et al., 2000). A series of studies was then performed in vivo to assess the functional importance of the identified genes.

\section{Materials and Methods}

Drugs and chemicals. ( \pm )MDMA hydrochloride salt and (+)methamphetamine (METH) hydrochloride salt were obtained from the National Institute on Drug Abuse (Bethesda, MD). Authenticity of the MDMA and METH samples used in these studies was verified by gas chromatography/mass spectroscopy. $\left[{ }^{33} \mathrm{P}\right] \mathrm{dCTP}$ was purchased from Amersham Biosciences (Piscataway, NJ). SDS (10\%), PAGE gel (18\%), polyvinylidene difluoride (PVDF) filters, Western loading buffer, and WesternBreeze chemiluminescent kit anti-mouse were purchased from Invitrogen (Carlsbad, CA). Mouse metallothionein (MT) primary antibody against horse embryonic MT(I+II) protein was purchased from Dako (Carpinteria, CA). Actin polyclonal antibody was purchased from Santa Cruz Biotechnology (sc1616; Santa Cruz, CA). 1-Methyl-4-phenyl1,2,3,6-tetrahydropyridine (MPTP), rabbit liver MT(I+II) protein, zinc acetate, Igepal CA-630, sodium deoxycholate, PMSF, aprotinin, sodium orthovanadate, dithioerythritol, and iodoacetamide were purchased from Sigma (St. Louis, MO). Primers were obtained from the DNA Core Facility at Johns Hopkins Medical Institutions (Baltimore, MD). The protein assay kit was obtained from Bio-Rad (Hercules, CA). The PCR kit and $\beta$-actin cDNA probe were obtained from Clontech (Palo Alto, CA). The $15 \mathrm{k}$ cDNA microarray chips containing 15,000 cDNA mouse gene fragments were provided by the Microarray Unit, National Institute on Aging (Baltimore, MD). Sources of the remaining drugs and chemicals have been described previously (Xie et al., 2002).

Animals. Male albino Swiss-Webster (SW) mice, weighing 25-30 gm, were purchased from Taconic (Germantown, NY). Male Mt1 and $M t 2$ double knock-out $(M t-K O)$ mice (129S7/SvEvBrd-M $t 1^{\text {tmlBri }} M t 2^{\text {tmlBri }}$ ) and the corresponding wild type (Mt-WT) (129S3/SvImj), weighing 22-28 gm, were purchased from The Jackson Laboratory (Bar Harbor, $\mathrm{ME})$. Mice were 8 weeks old at the time of drug treatment. Animals were housed and treated in clear acrylic cages in a temperature-controlled room $\left(21 \pm 1^{\circ} \mathrm{C}\right)$. As specified below, different doses of MDMA and different dosing regimens were used in the various experiments. Animal care and experimental manipulations were approved by the Institutional Animal Care and Use Committee at the Johns Hopkins University School of Medicine and were in accordance with the National Institutes of Health Guide for the Care and Use of Laboratory Animals. The facility for housing and care of the animals is accredited by the American Association for the Assessment and Accreditation of Laboratory Animal Care.

WIN35,428 blockade of MDMA-induced toxicity to DA neurons in SW mice. Mice ( $n=6$ per group) were treated with MDMA $(47 \mathrm{mg} / \mathrm{kg}$, s.c.) alone, WIN35,428 (12.5 mg/kg, i.p.) alone, WIN35,428 (12.5 mg/kg, i.p., immediately before and at several times after) plus MDMA $(47 \mathrm{mg} / \mathrm{kg}$, s.c.), or saline, at room temperature $\left(21 \pm 1^{\circ} \mathrm{C}\right)$. Rectal temperatures were measured for at least $6 \mathrm{hr}$ after drug administration. Mice were killed 1 week after treatment for measurement of brain biogenic amines, as below. All drug doses are expressed as the base.

Monoamine determinations. One week after drug administration, concentrations of DA and 5-HT in mouse striatum were measured by means of HPLC coupled with electrochemical detection, as described previously (Ricaurte et al., 1992).

Dissection of ventral midbrain/substantia nigra. The ventral midbrain containing the substantia nigra (pars compacta and pars reticulata) was isolated following the guidelines of Heffner et al. (1980), adapted for the mouse.

Microarray studies. As shown previously (Xie et al., 2002), microarray studies were performed in combination with a pharmacological strategy designed to facilitate recognition of changes in gene expression patterns that were linked to the neurotoxic process. In the current studies, MDMA was the compound under investigation, and microarray chips containing 15,000 mouse cDNA gene fragments were used (Tanaka et al., 2000). Substantia nigra tissue used for microarray studies was collected from SW mice from all four treatment groups (see above) $8 \mathrm{hr}$ after drug administration ( $n=16-20$ per group). The procedures for RNA isolation, probe labeling, and microarray hybridization have been described previously (Xie et al., 2002). Replicates were performed at least three times. As expected, many mRNAs were either induced or repressed by MDMA. However, only a few were influenced "selectively" (i.e., possibly linked with MDMA-induced toxicity to DA neurons), in which selectivity is operationally herein defined as mRNAs changes that occur to a significantly greater extent after MDMA alone compared with either WIN35,428 alone or MDMA in the presence of WIN35,428 (which prevents MDMA-induced toxicity to DA neurons).

Statistical analysis of microarray data. Data were analyzed using MS Excel (Microsoft, Seattle, WA) and Array Pro Analyzer (Media Cybermetics Inc., Silver Spring, MD). $\mathrm{z}$ transformation, $\mathrm{z}$ ratios, and $\mathrm{z}$ tests were used for data analysis (Vawter et al., 2001). Briefly, raw intensity data for each gene were first logarithmically transformed, and then $\mathrm{z}$ scores were calculated by subtracting the average gene intensity (calculated from the sum of all data points) from the log intensity value of each gene and dividing that result by the SD of all of the measured intensities. Gene expression differences between any two experiments were calculated by taking the difference between the observed gene $\mathrm{z}$ scores. $\mathrm{z}$ ratios express these differences in terms of their relationship to the SD of the distribution of all the observed gene changes. The significance of the $\mathrm{z}$ difference between the various treatment conditions (e.g., MDMA vs saline) was tested using the standard two-sample $\mathrm{z}$ test for comparison. A value of $p<0.05$ was considered significant.

Sequencing of Mt1 and Mt2 cDNA fragments. DNA sequencing was performed to confirm the specific genes of interest spotted on the cDNA microarray. Briefly, PCR products of $M t 1$ and $M t 2$ cDNA fragments ( 0.5 $\mu \mathrm{g}$ ) were reamplified by PCR using the following pair of universal primers: 5'-CTGCAAGGCGATTAAGTTGGGTAAC-3 (25 $\mu \mathrm{M})$ as the upstream primer and 5'-GTGAGCGGATAACAATTTCACACAGGAAACAGC-3 $(25 \mu \mathrm{M})$ as the downstream primer. PCR was performed under the following conditions: $95^{\circ} \mathrm{C}$ for $2 \mathrm{~min}$, followed by $95^{\circ} \mathrm{C}$ for $1 \mathrm{~min}$, $64^{\circ} \mathrm{C}$ for $1 \mathrm{~min}, 72^{\circ} \mathrm{C}$ for $2 \mathrm{~min} 15 \mathrm{sec}$, for 32 cycles, and a final extension time of $10 \mathrm{~min}$ at $72^{\circ} \mathrm{C}$. PCR products were cut from the agarose gel after electrophoresis, purified, and then sequenced. A BLAST (basic local alignment search tool) program (www.ncbi.nlm.nih.gov) was used to match and confirm specific genes as labeled on the cDNA microarray.

cDNA probe synthesis and Northern blot analysis for Mt1 and Mt2 $m R N A s$. DNA probes for $M t 1$ and $M t 2$ were derived from the PCR products used to generate the cDNA microarray after being sequenced, as described above. Probes were radiolabeled using a random primer labeling system in the presence of $\left[{ }^{33} \mathrm{P}\right] \mathrm{dCTP}$. $\beta$-Actin cDNA was used as an internal control to calibrate the loading amount of total RNA. Substantia nigra tissue used for Northern blot analysis was collected from SW mice from all four treatment groups (see above) $8 \mathrm{hr}$ after drug administration and from two treatment groups (MDMA and saline) 2, 4, 8, 12, or $24 \mathrm{hr}$ after drug administration ( $n=16-20$ per group). Extraction of total RNA, hybridization, washing and exposure of the filter, image capture, and semiquantitative analysis were all as described previously (Xie et al., 2002).

Western blot analysis of $M T(I+I I)$ protein. Mice were treated with MDMA (47 mg/kg, s.c.), METH (45 mg/kg, s.c.), MPTP (40 mg/kg, i.p.), zinc acetate $(5 \mathrm{mg} / \mathrm{kg}$, i.p.), or saline and killed 2, 4 (only for zinc), 6, 8 (only for zinc), 12, or $24 \mathrm{hr}$ later ( $n=5-7$ per group). Ventral midbrain tissues were dissected and homogenized in radioimmunoprecipitation assay buffer ( $4 \mathrm{ml}$ of buffer per gram of tissue) containing $1 \times$ PBS, $1 \%$ Igepal CA-630, 0.5\% sodium deoxycholate, $0.1 \%$ SDS, $0.1 \mathrm{mg} / \mathrm{ml} \mathrm{PMSF}$, $30 \mu \mathrm{l} / \mathrm{ml}$ aprotinin, and $1 \mathrm{~mm}$ sodium orthovanadate. The lysate was incubated on ice for $30 \mathrm{~min}$ in the presence of an additional $0.1 \mathrm{mg} / \mathrm{ml}$ PMSF and then centrifuged at $10,000 \times g$ for $10 \mathrm{~min}$. The supernatant was collected and centrifuged as before. The resulting supernatant was then collected for determination of protein concentration using a protein assay kit, according to the instructions of the manufacturer or stored at $-70^{\circ} \mathrm{C}$ until use. The method for MT protein detection was based on a published protocol (Lane, 1978), with a minor modification. Briefly, fresh dithioerythritol $(0.25 \mathrm{M})$ was mixed with the Western loading buffer and protein sample $(4 / 16 / 16 \mathrm{v} / \mathrm{v} / \mathrm{v})$, heated for $2 \mathrm{~min}$ in a boiling water bath, and cooled. Iodoacetamide $(0.5 \mathrm{M})$ was then added $(1 / 16 \mathrm{v} / \mathrm{v})$, and 
the sample was incubated for $15 \mathrm{~min}$ at $50^{\circ} \mathrm{C}$. Protein was loaded at 50 $\mu \mathrm{g} / \mathrm{lane}$ on $18 \%$ SDS-polyacrylamide gel, followed by electrophoresis and blotting onto a PVDF membrane. Incubation with a monoclonal mouse antibody, raised against horse MT(I+II) protein, was performed with a titer of 1:120. A chemiluminescent immunodetection kit was used to visualize signals. Actin was used to correct the loading protein amount. Band intensity was semiquantitatively analyzed using the NIH Image program Image J (http://rsb.info.nih.gov/ij/).

MDMA-induced dopaminergic neurotoxicity in Mt1/Mt2 double KO and wild-type mice. Adult male Mt1 and Mt2 double KO (129S7/ SvEvBrd-Mt1 $\left.{ }^{\mathrm{tmlBri}} M t 2^{\mathrm{tmlBri}}\right)$ and wild-type (129S3/SvImj) mice were used ( $n=10$ per group). Mice were treated with either MDMA (30 $\mathrm{mg} / \mathrm{kg}$, i.p.; $2 \mathrm{hr}$ intervals, four times) or saline. Rectal temperatures were measured for $8 \mathrm{hr}$ after drug administration, and all mice were killed 1 week after treatment to measure striatal biogenic amines, as above.

Effect of zinc on MDMA-induced toxicity to DA neurons in SW mice. Adult male SW mice were treated with MDMA (41 mg/kg, s.c.) alone, zinc acetate alone (5 mg/kg, i.p.), MDMA (41 mg/kg, s.c.) plus zinc acetate $(5 \mathrm{mg} / \mathrm{kg}$, i.p., immediately before MDMA), or saline at room temperature ( $n=7$ per group). Rectal temperatures were measured for 6 $\mathrm{hr}$ after drug administration, and all mice were killed 1 week after treatment to measure striatal biogenic amines, as described above.

Effect of exogenous MT(I+II) protein on MDMA-induced toxicity to DA neurons in SW mice. Adult male SW mice were treated with MDMA (47 $\mathrm{mg} / \mathrm{kg}$, s.c.) alone, MT(I+II) protein $(3.2 \mathrm{mg} / \mathrm{kg}$, i.p.; $2 \mathrm{hr}$ intervals, four times) alone, MDMA (47 mg/kg, s.c.) plus MT (I+II) $(3.2 \mathrm{mg} / \mathrm{kg}$, i.p.; 2 $\mathrm{hr}$ intervals, four times), or saline at room temperature $(n=10-16$ per group). The first dose of MT was administered $1 \mathrm{hr}$ before MDMA treatment. Rectal temperatures were measured for $6 \mathrm{hr}$ after first administration, and all mice were killed 1 week after treatment to measure striatal biogenic amines, as described above.

Statistical analysis of biochemical data. HPLC data were analyzed by one-way ANOVA, followed by Duncan's multiple range post hoc comparisons, when appropriate. Results were considered significant when $p<0.05$, using a two-tailed test. Data analysis was performed using the Statistical Program for the Social Sciences (SPSS for Windows, release 6; SPSS, Chicago, IL).

\section{Results \\ MDMA-induced selective dopaminergic neurotoxicity and neuroprotection by WIN35,428}

MDMA, when administered to SW mice ( $47 \mathrm{mg} / \mathrm{kg}$, s.c.), produced a significant long-term depletion of striatal DA (Fig. 1a) with no significant change in 5-HT (Fig. 1b). The DAT inhibitor WIN35,428 completely blocked the long-term MDMA-induced DA depletion (Fig. 1a). Alone, WIN35,428 did not produce a significant effect on striatal DA measured. The protective effect of WIN35,428 was not mediated by any resulting change in core temperature, because the acute hyperthermic response produced by MDMA was also observed in mice administered MDMA in combination with WIN35,428 (Fig. 1c). Notably, WIN35,428 could exert neuroprotective effects even if given up to $4 \mathrm{hr}$ (but not $6 \mathrm{hr}$ ) after MDMA (Fig. 1d), suggesting that events critical to MDMA neurotoxicity occur within 4-6 hr of MDMA exposure.

\section{Differential expression of $M t 1$ and $M t 2$ genes at the mRNA level}

cDNA microarray studies identified a number of genes whose expression appeared to link MDMA-induced toxicity to DA neurons (Table 1). Of these, $M t 1$ and $M t 2$ were among the most affected. In particular, both $M t 1$ and $M t 2$ genes were upregulated at the mRNA level in the substantia nigra $8 \mathrm{hr}$ after MDMA administration, with $\mathrm{z}$ ratios of 5.3 and 4.9 , respectively $(p<$ 0.05, compared with control; Table 1). Expression of Mt1 and Mt2 was also increased in mice treated with MDMA plus WIN35,428 but to a lesser extent (Table 1). Differences between a
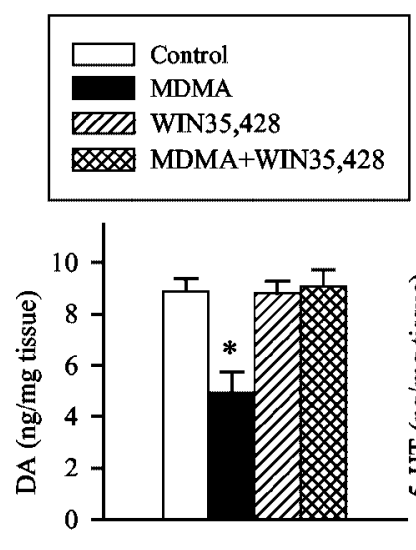

c
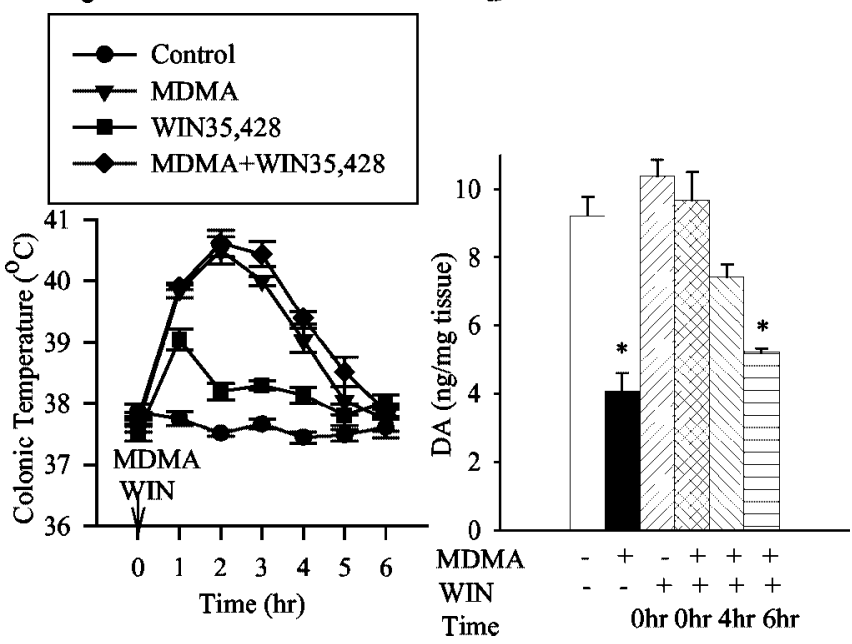

Figure 1. Effect of MDMA, alone or in combination with WIN35,428 administered immediately before $(a-c)$ or 4 and $6 \mathrm{hr}$ after (d) MDMA treatment, on striatal DA $(a, d), 5-\mathrm{HT}(b)$, and core temperature $(c)$ in SW mice. Mice received vehicle (saline), MDMA (47 mg/kg, s.c.), WIN35,428 (12.5 mg/kg, i.p.), or MDMA (47 mg/kg, s.c.) plus WIN35,428 (12.5 mg/kg, i.p, immediately before or 4 and $6 \mathrm{hr}$ after MDMA), at an ambient temperature of $21 \pm 1^{\circ}$. Note that WIN35,428 can exert neuroprotective effects even when given up to $4 \mathrm{hr}$ (but not $6 \mathrm{hr}$ ) after MDMA (d). For DA and 5-HT determinations, mice were killed 1 week after drug treatment. Results shown represent the mean \pm SEM for each group ( $n=6-8$ per group). In all cases, statistically significant differences represent $p<0.05$ (ANOVA, followed by Duncan's multiple range test). ${ }^{*}$ indicates different from control.

the $\mathrm{z}$ ratios of MDMA/saline and MDMA plus WIN35,428/saline (5.3 vs 3.1 for $M t 1 ; 4.9$ vs 3.2 for $M t 2)$ were significant $(p<0.05)$. WIN35,428 alone did not alter $M t 1$ and $M t 2$ expression ( $p>$ 0.05 , compared with control) (Table 1).

\section{Sequencing of $M t 1$ and $M t 2$ cDNA fragments}

To ensure that the PCR products of the cDNA fragments were correctly spotted on the cDNA microarray without contamination, PCR products of $M t 1$ and $M t 2$ cDNA fragments were reamplified by PCR and partially sequenced, using both upstream and downstream universal primers. All proved to be the expected genes when compared with the GenBank using the BLAST program in the National Center for Biotechnology Information.

Northern blot analysis to confirm the cDNA microarray data To confirm the microarray data, $M t 1$ and $M t 2$ mRNA levels in substantia nigra tissue were measured by Northern blot analysis. As shown in Figure 2, MDMA administration resulted in an up- 
Table 1. Ten genes identified by cDNA microarray technique based on statistical z ratio analysis in response to MDMA and WIN35,428 treatment, alone or in combination

\begin{tabular}{|c|c|c|c|c|c|c|}
\hline Gene & Function & $\mathrm{M} / \mathrm{C}$ & $\mathrm{MW} / \mathrm{C}$ & $\mathrm{W} / \mathrm{C}$ & M/MW & M/W \\
\hline Metallothionein-1 (Mt1) & Free radical scavenger & $5.3^{*}$ & $3.1^{*}$ & 1.4 & $2.2^{*}$ & $3.5^{*}$ \\
\hline Metallothionein-2 (Mt2) & Free radical scavenger & $4.9^{*}$ & $3.2^{*}$ & 0.4 & $1.8^{*}$ & $4.1^{*}$ \\
\hline Serum and glucocorticoid-dependent protein kinase ( $S g k$ ) & Ion regulation & $3.0^{*}$ & 1.4 & 0.5 & $1.7^{*}$ & $2.5^{*}$ \\
\hline Cystatin C (Cst3) & Cysteine protease inhibitor & $2.0^{*}$ & 0.0 & 0.0 & $2.1^{*}$ & $1.9^{*}$ \\
\hline Eukaryotic translation elongation factor $1 \alpha 1$ (Ef1) & mRNA translation & $1.7^{*}$ & -0.1 & -0.1 & $1.9^{*}$ & $1.8^{*}$ \\
\hline NADH dehydrogenase unit 1 (Nd1) & Energy generation & $1.7^{*}$ & 0.1 & $0.9^{*}$ & $1.8^{*}$ & $0.9^{*}$ \\
\hline Mitogen-activated protein kinase 14 (Mapk14) & Signal transduction & $1.6^{*}$ & 0.0 & 0.2 & $1.7^{*}$ & $1.4^{*}$ \\
\hline Histone acetyltransferase 1 (Hat1) & Gene transcription & $1.5^{*}$ & 0.4 & 0.6 & $1.3^{*}$ & $1.1^{*}$ \\
\hline Eukaryotic translation elongation factor 4e-like protein (Ef4) & mRNA translation & $1.5^{*}$ & 0.3 & 0.6 & $1.3^{*}$ & 0.9 \\
\hline Microtubule-actin cross-linking factor 7 (Macf7) & Cytoskeletal linker & $-3.5^{*}$ & -0.9 & -0.7 & $-2.9^{*}$ & $-2.8^{*}$ \\
\hline
\end{tabular}

For drug treatment details, see Figure 1 legend. For selection criteria, see Materials and Methods. M/C, z ratio of MDMA compared with control; MW/C, z ratio of MDMA plus WIN35,428 compared with control; W/C, z ratio of WIN35,428 compared with control; M/MW, z ratio of MDMA compared with MDMA plus WIN35,428; M/W, z ratio of MDMA compared with WIN35,428.

${ }^{*} p<0.05$, statistical significance.

$\mathbf{a}$

\section{Control MDMA MW WIN}

Mt1

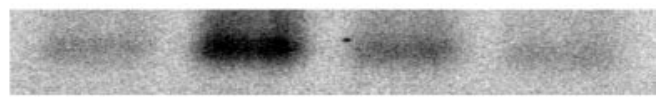

$\beta$-actin

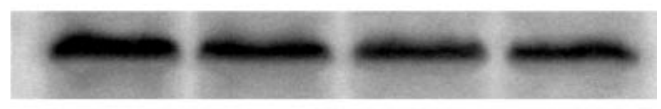

b

\section{Control MDMA MW WIN}

Mt2

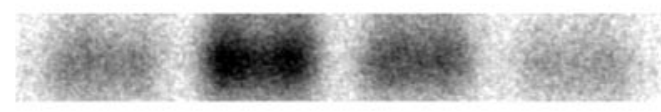

$\beta$-actin

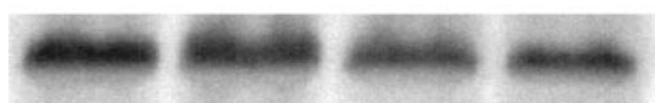

Figure 2. Differential expression of $M t 1(a)$ and $M t 2(b)$ mRNA levels $8 \mathrm{hr}$ after treatment, as detected by Northern blot analyses. A $\beta$-actin cDNA probe was used as internal control. For drug treatment details, see Figure 1 legend ( $n=16-20$ per group). MW, MDMA plus WIN35,428; WIN, WIN35,428 alone. Quantitative analysis of Northern blot data, expressed as fold change for MDMA compared with control, MW compared with control, and WIN compared with control, after normalization of RNA loading amount by $\beta$-actin intensity, were 3.8-, 2-, and 1.6-fold, respectively for $M t 1$, and 3.5-, 2.8-, and 1.4-fold, respectively, for Mt2.

regulation of $M t 1$ and $M t 2$ (3.8- and 3.5-fold, respectively). WIN35,428 alone had no significant effect. In keeping with the microarray results, mice treated with WIN35,428 before MDMA showed an upregulation of $M t 1$ and $M t 2$ but not to the same extent as mice administered MDMA alone (2- and 2.8-fold, respectively).

Northern blot analysis for the time course of MDMA-induced changes in $M t 1$ and $M t 2$ mRNA levels

To characterize the time course of changes in $M t 1$ and $M t 2$ mRNA expression, substantia nigra tissue was collected at 2, 4, 8, 12 , or $24 \mathrm{hr}$ after MDMA treatment. $M t 1$ and $M t 2$ were dynamically upregulated over the $24 \mathrm{hr}$ period studied (Fig. 3a,b), peaking $4 \mathrm{hr}$ after MDMA administration, with a maximum change of 4.5-fold for $M t 1$ and 3.5-fold for Mt2. a

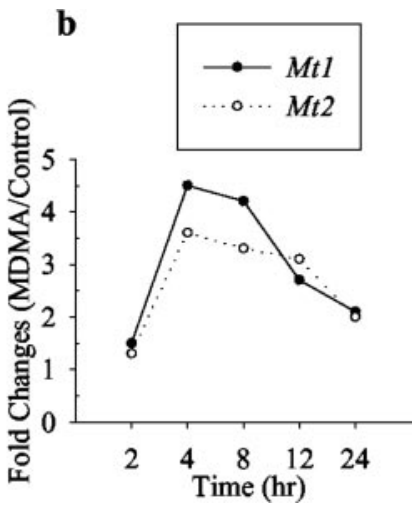

Figure 3. Time course of $M t 1$ and Mt2 mRNAs after MDMA treatment. $a$, A representative Northern blot image 4-12 hr after MDMA treatment. $b$, Quantitative analyses of the of mRNA levels 2-24 hr after MDMA treatment, presented as fold changes, compared with the salinetreated control animals. Mice were administered MDMA ( $47 \mathrm{mg} / \mathrm{kg}$, s.c.) or saline and killed 2, $4,8,12$, or $24 \mathrm{hr}$ later ( $n=16-20$ per group). A $\beta$-actin cDNA probe was used as an internal control.

Western blot analysis for the time course of MDMA-induced changes in MT protein

To determine whether the observed increase in $M t$ mRNA levels resulted in an increase in $\mathrm{MT}$ protein levels, an antibody to both MT-I and MT-II proteins was used to detect MT(I+II) protein levels 2, 6, 12, and $24 \mathrm{hr}$ after MDMA treatment. MT(I+II) protein was dynamically upregulated over the $24 \mathrm{hr}$ period studied and peaked $12 \mathrm{hr}(\sim 3.3$-fold change $)$ after MDMA treatment (Fig. 4).

MDMA-induced toxicity to DA neurons in Mt1/Mt2 double KO and wild-type mice

To study the functional role of $M t(I+I I)$ genes in the development of MDMA-induced toxicity to DA neurons, $M t$-KO mice were studied. Compared with $M t$-WT mice, $M t$-KO mice showed larger DA deficits 1 week after a neurotoxic dose regimen of MDMA (30 mg/kg, s.c., $2 \mathrm{hr}$ intervals, four times) (Fig. $5 a$ ). $M t$-KO mice showed no significant depletion of 5-HT (data not shown). No significant differences in either the baseline temperature or MDMA-induced hyperthemia were observed between $M t$-KO and $M t$-WT mice (Fig. $5 b$ ).

Effect of zinc on MT protein expression and MDMA-induced neurotoxicity in SW mice

Zinc has been demonstrated to enhance the expression of endogenous $M t(I+I I)$ mRNA and protein expression, both in vitro and 
a

Control M2h M6h M12h M24h

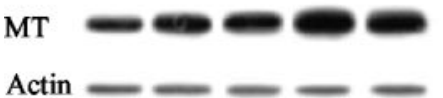

$\mathbf{b}$

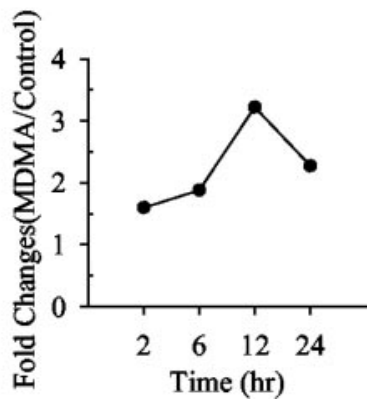

Figure 4. Time course of $\mathrm{MT}(\mathrm{I}+\mathrm{II})$ protein expression after MDMA treatment. $a$, A representative Western blot image 2-24 hr after MDMA treatment. $b$, Quantitative analyses of the protein levels 2-24 hr after MDMA treatment, presented as fold changes, compared with saline-treated control animals. Mice were administered MDMA ( $47 \mathrm{mg} / \mathrm{kg}$, s.c.) or saline and killed 2, 6, 12, or $24 \mathrm{hr}$ later ( $n=5-7$ per group). An actin antibody was used as an internal control.

a

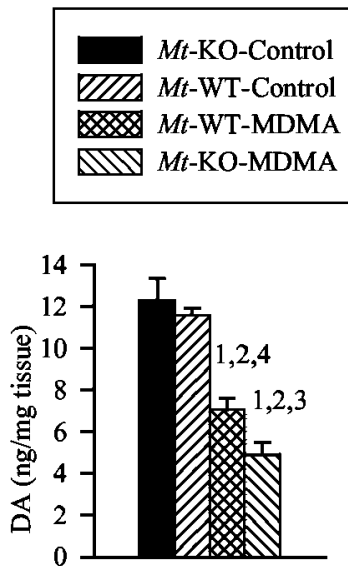

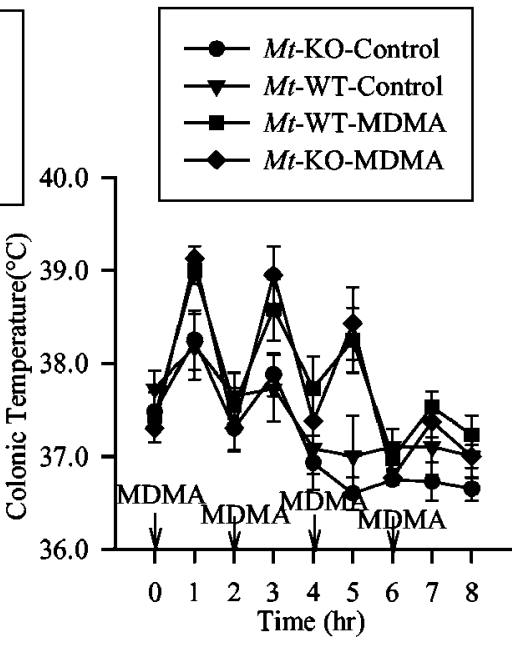

Figure 5. Effect of MDMA on striatal DA $(a)$ and core temperature ( $b$ ) in Mt-KO and Mt-WT. All mice received either vehicle (saline) or MDMA ( $30 \mathrm{mg} / \mathrm{kg}$, s.c.; 2 hr intervals, four times). Core temperature was measured during drug treatment. For DA determinations, mice were killed 1 week after drug treatment. Results shown represent the mean \pm SEM for each group $(n=4$ for each control group; $n=6$ for each MDMA group). In all cases, statistically significant differences represent $p<0.05$ (ANOVA, followed by Duncan's multiple range test). $a, 1$, Different from Mt-K0 control; 2, different from Mt-WT control; 3, different from Mt-WT MDMA; 4, different from Mt-KO MDMA.

in vivo (Durnam and Palmiter, 1981; Aschner et al., 1998; Hidalgo et al., 2001; Penkowa et al., 2001). To examine whether endogenously induced overexpression of $M t(I+I I)$ genes could protect against MDMA-induced DA neurotoxicity, the effect of zinc was evaluated. As shown in Figure $6 a$, peripheral administration of zinc $(5 \mathrm{mg} / \mathrm{kg})$ increased MT protein levels in the substantia nigra region at all time points examined, peaking at $8 \mathrm{hr}$, at which time there was approximately a sixfold change. Administration of zinc immediately before MDMA treatment conferred complete protection against MDMA-induced DA deficits (Fig. $6 b$ ), whereas administration of zinc alone had no significant longterm effect on DA. There was no significant difference between the acute hyperthermic responses of mice treated with MDMA alone and MDMA plus zinc pretreatment (Fig. 6c).

a

b

c
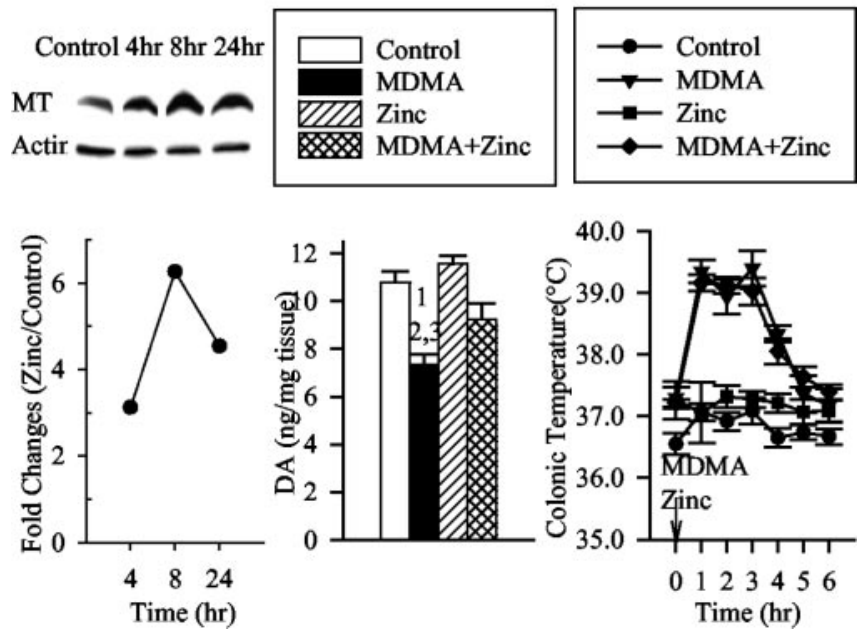

Figure 6. Effect of zinc acetate on MT protein expression in substantia nigra region (a), MDMA neurotoxicity on striatal DA (b), and core temperature in SW mice (c). Mice received vehicle (saline), zinc acetate (5 mg/kg, i.p.), MDMA (41 mg/kg, s.c.), or MDMA ( $41 \mathrm{mg} / \mathrm{kg}$, s.c.) plus zinc acetate ( $5 \mathrm{mg} / \mathrm{kg}$, i.p, immediately before MDMA). For DA determinations, mice were killed 1 week after drug treatment. Results shown represent the mean \pm SEM for each group ( $n=5-7$ per group). In all cases, statistically significant differences represent $p<0.05$ (ANOVA, followed by Duncan's multiple range test). $b, 1$, Different from control; 2 , different from zinc acetate; 3 , different from MDMA plus zinc acetate. a

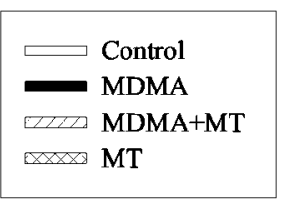

b

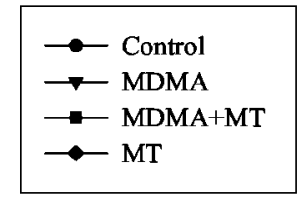

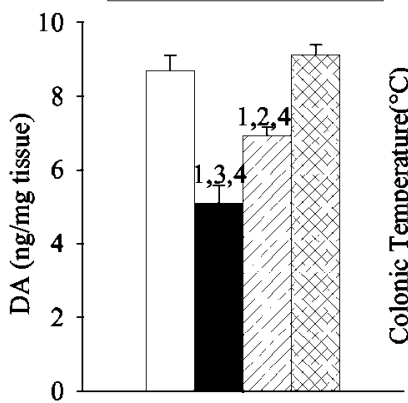

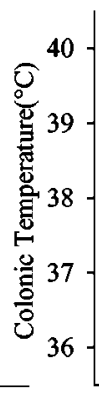

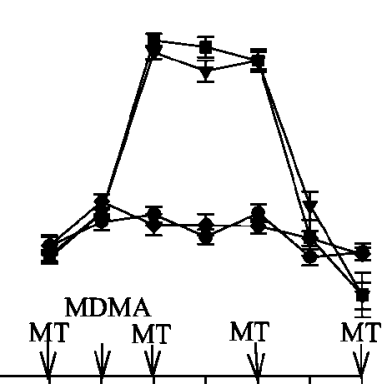

$-1 \mathrm{hr} 0 \mathrm{hr} 1 \mathrm{hr} 2 \mathrm{hr} 3 \mathrm{hr} 4 \mathrm{hr} 5 \mathrm{hr}$ Time (hr)
Figure 7. Effect of exogenous MT(I+II) protein and MDMA, alone or in combination, on striatal DA ( $a$ ) and core temperature ( $b$ ) in SW mice. Mice received vehicle (saline), MDMA (47 $\mathrm{mg} / \mathrm{kg}$, s.c.), MT(I+II) protein (3.2 mg/kg, i.p., $2 \mathrm{hr}$ intervals, four times) or MDMA plus MT (I+ II) protein with the first dose of MT (I+II) administered $1 \mathrm{hr}$ before MDMA administration. For DA determinations, mice were killed 1 week after drug treatment. Results shown represent the mean \pm SEM for each group ( $n=10-16$ per group). In all cases, statistically significant differences represent $p<0.05$ (ANOVA, followed by Duncan's multiple range test). a, 1, Different from control; 2, different from MDMA; 3 , different from MDMA plus MT; 4, different from MT.

\section{Effect of exogenous MT protein on}

MDMA-induced neurotoxicity

Administration of exogenous MT(I+II) protein $1 \mathrm{hr}$ before and 1,3 , and $5 \mathrm{hr}$ after MDMA provided partial but significant protection against MDMA-induced DA deficits $(p<0.05)$ (Fig. 7a). $\mathrm{MT}(\mathrm{I}+\mathrm{II})$ protein itself did not result in a long-term depletion of 

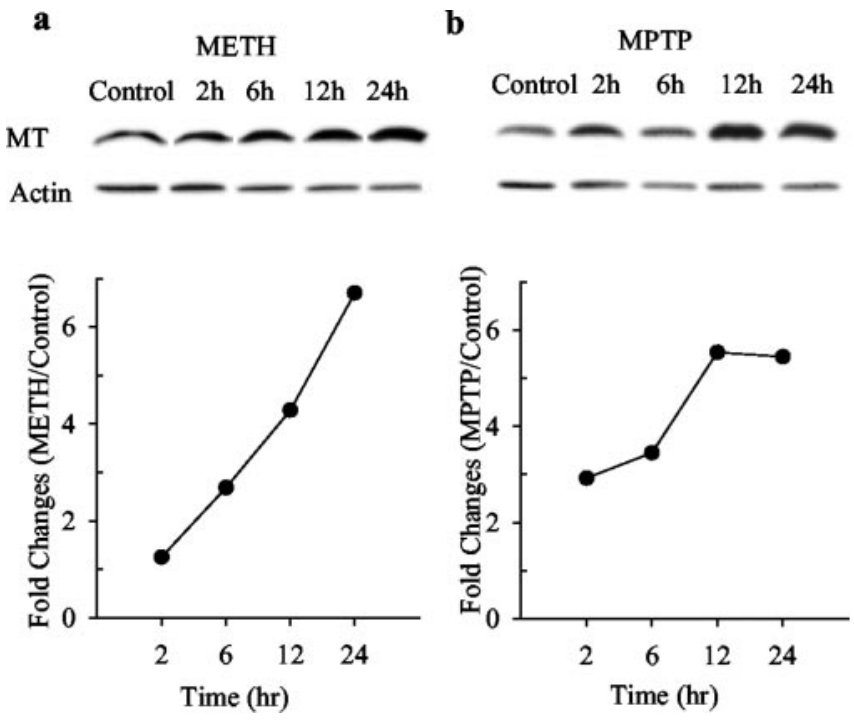

Figure 8. Time course of MT(I+II) protein expression 2-24 hr after METH ( $a$ ) and MPTP treatment $(b)$, with Western blot image and fold changes. Mice were administered METH (45 $\mathrm{mg} / \mathrm{kg}$, s.c.), MPTP ( $40 \mathrm{mg} / \mathrm{kg}$, i.p.), or saline and killed 2, 6, 12, or $24 \mathrm{hr}$ later ( $n=5-7 \mathrm{per}$ group). An actin antibody was used as an internal control.

DA (Fig. 7a). The MDMA-induced acute hyperthermic response was unaltered by MT(I+II) treatment, and administration of $\mathrm{MT}(\mathrm{I}+\mathrm{II})$ alone had no effect on core temperature (Fig. $7 b$ ).

\section{METH- and MPTP-induced changes in MT protein}

To determine whether the present findings with MDMA generalized to other drugs known to produce toxic effects on DA neuron, we tested the effects of two other drugs with known DA neurotoxic potential in mice, METH and MPTP. In particular, we examined whether the observed increase in $\mathrm{MT}(\mathrm{I}+\mathrm{II})$ protein after MDMA also occurred after neurotoxic doses of METH (45 $\mathrm{mg} / \mathrm{kg}$, s.c., resulting in $\sim 63 \%$ DA depletion 1 week later) (Xie et al., 2002), or MPTP (40 mg/kg, i.p., resulting in $\sim 65 \%$ DA depletion; data not shown). MT(I+II) protein levels, measured 2, 6, 12 , and $24 \mathrm{hr}$ after drug treatment, were also dynamically upregulated over the $24 \mathrm{hr}$ period studied and peaked $24 \mathrm{hr}(\sim 6.7$-fold change) after METH treatment (Fig. $8 a)$ and $12 \mathrm{hr}(\sim 5.5$-fold change) after MPTP treatment (Fig. $8 b$ ).

\section{Discussion}

Results from the present studies, obtained using cDNA microarray methods in combination with an approach designed to facilitate recognition of changes in gene expression relevant to the neurotoxic process, indicate that genes for $M t 1$ and $M t 2$ are differentially expressed in the setting of MDMA-induced toxicity to DA neurons. $M t 1$ and $M t 2$ are members of the metallothionein family, which are cysteine-rich, low-molecular-weight heavy metal (i.e., zinc) binding proteins found in all body tissues (for review, see Chung and West, 2004). In the mammalian CNS, expression of $M t 1$ and $M t 2$ occurs primarily in astrocytes, but low levels are also found in some neuronal populations. The $M t 3$ isoform is also found in both glial (astrocytes) and neuronal elements, with highest abundance in granule cells of the dentate gyrus in the hippocampus (for review, see Chung and West, 2004). In the present study, we observed differential expression of $M t 1$ and $M t 2$ mRNAs in the ventral midbrain that peaked at $\sim 4$ hr after MDMA treatment, followed by increases in MT-I and
MT-II protein levels that peaked $\sim 8 \mathrm{hr}$ later $(12 \mathrm{hr}$ after MDMA exposure).

The expression of $M t 1$ and $M t 2$ early in the course of MDMAinduced toxicity to DA neurons raises the question whether these proteins are directly involved in the toxic process, or whether they represent a response to neurotoxic injury. Several features of the current data suggest that $M t 1$ and $M t 2$ are increased in response to injury rather than as an integral part of the neurotoxic process. First, the timing of the $M t 1$ and $M t 2$ increases is later than that which would be predicted if these proteins were intrinsic to early DA neurotoxic mechanisms. In particular, the present results (Fig. 1), as well as previous studies (Meek et al., 1971; Fuller et al., 1975; Schmidt, 1987; Fuller and Henderson, 1994), indicate that critical early events in the neurotoxicity of MDMA and related drugs ( $p$-chloroamphetamine, methamphetamine, and $p$-chloromethamphetamine) occur $\sim 4-6 \mathrm{hr}$ after drug exposure. Beyond this critical window of time, uptake blockers are no longer effective in preventing MDMA-induced neurotoxicity, as demonstrated in the present study. The fact that MT(I+II) proteins peak $12 \mathrm{hr}$ after exposure suggests that they appear after the neurotoxic process is well underway, although this observation does not preclude the possibility that lower levels of MT protein at earlier time points play a role in toxic process. Second, although $M t 1$ and $M t 2$ are differentially expressed after MDMA treatment, they also increase, to a lesser degree, after treatment with MDMA plus WIN35,428, when no DA neurotoxicity occurs. Most likely, this is secondary to some form of neuronal stress other than DA neurotoxicity that occurs when MDMA is given in combination with WIN35,428. Third, the increased vulnerability of $M t$-KO mice to MDMA-induced toxicity to DA neurons also suggests a neuroprotective role rather than a toxic role for MT proteins. Finally, the fact that manipulations that increase endogenous $\mathrm{MT}(\mathrm{I}+\mathrm{II})$ production, in addition to exogenous MT(I+II) administration, were both found to be neuroprotective, either completely or in part, in the setting of MDMA administration is in keeping with the view that $M t 1$ and $M t 2$ are expressed in response to injury, as either neuroprotectants or substances that promote recovery from neuronal stress or injury.

Previous studies have suggested that MT proteins have neuroprotective effects after treatment with other dopaminergic neurotoxins. For example, MPTP-induced toxicity toward DA neurons was attenuated by the administration of the MT inducers cadmium and dexamethasone (Rojas and Rios, 1997), whereas 6-hydroxydopamine-induced toxicity to DA neurons was more severe in $M t 1 / M t 2-\mathrm{KO}$ mice compared with the wild type (Asanuma et al., 2002). An apparent conflicting report (Rojas and Klaassen, 1999) failed to find differences between $M t$-KO mice compared with the wild type after exposure to MPTP. However, negative findings obtained in that study may have been related to differences in the age of animals used, as well as different survival times used by those investigators. Studies in our own laboratory indicate that MT is elevated in the substantia nigra of MPTP- and METH-treated mice and that these increases are similar to those seen in MDMA-treated mice (Fig. 8).

The mechanisms by which MT proteins might proffer protection from DA neurotoxicity are not known, but current knowledge about their neuroanatomical localization and neurobiology suggest at least two possibilities. In particular, MT(I+II) proteins are abundant in fibrous and protoplasmic astrocytes throughout the brain yet, as alluded to above, are conspicuously absent from neuronal populations (Aschner, 1996; Chung and West, 2004). The positioning of astrocytes and their foot processes raises the possibility that they may be in a favorable position to remove 
cytotoxic stimuli from the extracellular fluid and indirectly protect juxtaposed neurons or repair neuronal damage. With regard to their neurobiology, MT(I+II) proteins are known to function as thiol donors as well as reactive oxidative species (ROS) scavengers (Lazo et al., 1995; Hussain et al., 1996; Ebadi et al., 1998). Several laboratories have implicated ROS in MDMA-induced neurotoxicity (Cadet et al., 1995, 2001; Jayanthi et al., 1999; Colado et al., 2001; Camarero et al., 2002), suggesting that $\mathrm{MT}(\mathrm{I}+\mathrm{II})$ induction may be part of a neuroprotective mechanism in the CNS (Hussain et al., 1996; Campagne et al., 1999; Penkowa et al., 1999, 2000; Chung et al., 2003). Clearly, the neuroprotective actions of MT could also be mediated by other mechanisms, including MT-related modulation of proinflammatory cytokines (Penkowa and Hildago, 2001) or growth and tissue repair factors (Penkowa and Hidalgo, 2003).

The experiments involving peripheral injection of zinc and purified MT were conducted after the primary experiments in our study were completed and were intended to provide supportive evidence for the principal finding of our study (namely, that increased expression of MT appears to be part of a compensatory neuroprotective mechanism in the setting of MDMA neurotoxicity). It should be emphasized, however, that these supplemental experiments are not conclusive in and of themselves and that to fully understand the mechanisms of neuroprotection associated with the peripheral administration of zinc and MT protein, additional experiments would be necessary. Indeed, it is possible that the protective effects of peripherally administered zinc and/or MT might involve peripheral rather than central actions, because zinc is known to induce peripheral as well as central MT and because brain concentrations of MT after peripheral MT administration were not measured. That having been said, there are reasons to believe that peripheral administration of zinc and MT might lead to increases in brain MT, thus providing neuroprotection. First, peripheral zinc increased central MT expression (Fig. 6a) and afforded complete neuroprotection. Second, exogenous MT is a small protein (only 6-7 kDa) that has been found to cross the blood-brain barrier (BBB) in a rat encephalitis model (Penkowa and Hidalgo, 2000), indicating that, at least under some conditions (i.e., those that interfere with the BBB, such as encephalitis), peripherally administered MT can cross the BBB to gain access to the brain parenchyma. Third, hyperthermia (core temperature $\sim 40^{\circ} \mathrm{C}$ for $45 \mathrm{~min}$ ) on the order of that produced by MDMA (core temperature $\sim 40^{\circ} \mathrm{C}$ for almost $3 \mathrm{hr}$ ) (Figs. $1 c, 7 b$ ) has also been found to alter the BBB (Wijsman and Shivers, 1993). Therefore, although by no means definitive, given the finding of differentially increased $M t$ expression in the setting of MDMA-induced toxic effects toward brain DA neurons, it is reasonable to postulate that central MT, at least in part, may play a role in the neuroprotective effects observed after peripheral zinc and MT administration.

Although we have not investigated the induction of $M t 1$ and $M t 2$ gene expression in other lesion models, there are reports of upregulation of $M t 1$ and $M t 2$ gene expression in other models of brain injury. For example, the excitotoxin kainic acid induces increases in $M t 1 \mathrm{mRNA}$ level in areas with extensive damage (e.g., piriform cortex) (Dalton et al., 1995). Other chemically induced brain lesions also lead to upregulation of $M t 1$ and $M t 2$ gene expression (Hidalgo et al., 2001). However, downregulation of MT protein expression has been reported in human diseases caused by prions (Kawashima et al., 2000). Clearly, the exact nature and timing of the $M t 1$ and $M t 2$ response to different toxin lesion models needs to be further investigated.

In summary, the present results indicate that $M t 1$ and $M t 2$ genes are dynamically and differentially expressed in the setting of MDMA-induced toxicity to DA neurons and that overexpression of MT protein can protect against toxic effects of MDMA on DA neurons in mice. When the timing of $M t 1$ and $M t 2$ mRNA and protein expression is considered, along with previous data suggesting that these proteins have protective effects against other DA neurotoxins, it seems likely that $M t 1$ and $M t 2$ are expressed in response to MDMA-induced toxicity on DA neurons rather than playing an active role in the toxic process. The possibility that MT proteins could play a neuroprotective role in idiopathic conditions in which DA neuronal injury occurs (e.g., Parkinson's disease) or under circumstances in which DA neurons are damaged by exogenous toxins (e.g., METH) merits further consideration.

\section{References}

Asanuma M, Miyazaki I, Higashi Y, Tanaka K, Haque ME, Fujita N, Ogawa N (2002) Aggravation of 6-hydroxydopamine-induced dopaminergic lesions in metallothionein-I and -II knock-out mouse brain. Neurosci Lett 327:61-65.

Aschner M (1996) The function of brain metallothionein. FASEB J 10:1129-1136.

Aschner M, Conklin DR, Yao CP, Allen JW, Tan KH (1998) Induction of astrocyte metallothioneins (Mts) by zinc confers resistance against the acute cytotoxic effects of methylmercury on cell swelling, $\mathrm{Na}^{+}$uptake, and $\mathrm{K}^{+}$release. Brain Res 813:254-261.

Cadet JL, Ladenheim B, Hirata H, Rothman RB, Ali S, Carlson E, Epstein C, Moran TH (1995) Superoxide radicals mediate the biochemical effects of methylenedioxymethamphetamine (MDMA): evidence from using $\mathrm{CuZn}$-superoxide dismutase transgenic mice. Synapse 21:169-176.

Cadet JL, Thiriet N, Jayanthi S (2001) Involvement of free radicals in MDMA-induced neurotoxicity in mice. Ann Med Interne (Paris) 152:IS57-IS59.

Camarero J, Sanchez V, O’Shea E, Green AR, Colado MI (2002) Studies, using in vivo microdialysis, on the effect of the dopamine uptake inhibitor GBR 12909 on 3,4-methylenedioxymethamphetamine ("ecstasy”)induced dopamine release and free radical formation in the mouse striatum. J Neurochem 81:961-972.

Campagne MV, Thibodeaux H, van Bruggen N, Gerlai R, Palmer JT, William SP, Lowe DG (1999) Evidence for a protective role of metallothionein-1 in focal cerebral ischemia. Proc Natl Acad Sci USA 96:12807-12875.

Chung RS, West AK (2004) A role for extracellular metallothioneins in CNS injury and repair. Neuroscience 123:595-599.

Chung RS, Vickers JC, Chung MI, West AK (2003) Metallothionein-IIA promotes initial neurite elongation and postinjury reactive neurite growth and facilitates healing after focal cortical brain injury. J Neurosci 23:3336-3342.

Colado MI, Camarero J, Mechan AO, Sanchez V, Esteban B, Elliott JM, Green AR (2001) A study of the mechanism involved in the neurotoxic action of 3,4-methylenedioxymethamphetamine (MDMA, "ecstasy") on dopamine neurons in mouse brain. Br J Pharmacol 134:1711-1723.

Dalton T, Pazdernik TL, Wagner J, Samson F, Andrews GK (1995) Temporalspatial patterns of expression of metallothionein-I and -III and other stress related genes in rat brain after kainic acid-induced seizures. Neurochem Int 27:59-71

Durnam DM, Palmiter RD (1981) Transcriptional regulation of the mouse metallothionein-I gene by heavy metals. J Biol Chem 256:5712-5716.

Ebadi M, Ramana Kumari MV, Hiramatsu M, Hao R, Pfeiffer RF, Rojas P (1998) Metallothionein, neurotrophins and selegiline in providing neuroprotection in Parkinson's disease. Restor Neurol Neurosci 12:103-111.

Fuller RW, Henderson MG (1994) Neurochemistry of halogenated amphetamines. In: Amphetamine and its analogs. Psychopharmacology, toxicology and abuse (Cho AK, Segal DS, eds), pp 209-242. San Diego: Academic.

Fuller RW, Perry K, Molloy BB (1975) Reversible and irreversible p-chloroamphetamine serotonin depletion by 4-chloroamphetamine. Eur J Pharmacol 33:119-124

Green AR, Mechan AO, Elliott JM, O'Shea E, Colado MI (2003) The pharmacology and clinical pharmacology of 3,4-methylenedioxymethamphetamine (MDMA, “ecstasy”). Pharmacol Rev 55:463-508. 
Heffner TG, Hartman JA, Seiden LS (1980) A rapid method for the regional dissection of the rat brain. Pharmacol Biochem Behav 13:453-456.

Hidalgo J, Aschner M, Zatta P, Vasak M (2001) Roles of the metallothionein family of proteins in the central nervous system. Brain Res Bull 55:133-145.

Hussain S, Slikker Jr W, Ali SF (1996) Role of metallothionein and other antioxidants in scavenging superoxide radicals and their possible role in neuroprotection. Neurochem Int 29:145-152.

Jayanthi S, Ladenheim B, Andrews AM, Cadet JL (1999) Overexpression of human copper/zinc superoxide dismutase in transgenic mice attenuates oxidative stress caused by methylenedioxymethamphetamine (Ecstasy). Neuroscience 91:1379-1387.

Johnston LD, O'Malley PM, Bachman JG (2004) Monitoring the future national results on adolescent drug use: overview of key findings, 2003. NIH publication number 04-5506. Bethesda, MD: National Institute on Drug Abuse.

Kawashima T, Doh K, Torisu M, Uchida Y, Furuta A, Iwaki T (2000) Differential expression of metallothioneins in human prion diseases. Dement Geriatr Cogn Disord 11:251-262.

Lane LC (1978) A simple method for stabilizing protein-sulfhydryl groups during SDS-gel electrophoresis. Anal Biochem 86:655-664.

Lazo JS, Kondo Y, Dellapiazza D, Michalska AE, Choo KHA, Pitt BR (1995) Enhanced sensitivity to oxidative stress in cultured embryonic cells from transgenic mice deficient in metallothionein I and II genes. J Biol Chem 270:5506-5510.

Logan BJ, Laverty R, Sanderson WD, Yee YB (1988) Differences between rats and mice in MDMA (methylenedioxymethylamphetamine) neurotoxicity. Eur J Pharmacol 152:227-234.

Meek JL, Fuxe K, Carlsson A (1971) Blockade of p-chloromethamphetamine induced 5-hydroxytryptamine depletion by chlorimipramine, chlorpheniramine and meperidine. Biochem Pharmacol 20:707-709.

O'Callaghan JP, Miller DB (1994) Neurotoxicity profiles of substituted amphetamines in the C57BL/6J mouse. J Pharmacol Exp Ther 270:741-751.

O'Shea E, Esteban B, Camarero J, Green AR, Colado MI (2001) Effect of GBR12909 and fluoxetine on the acute and long term changes induced by MDMA ("ecstasy") on the 5-HT and dopamine concentrations in mouse brain. Neuropharmacology 40:65-74.

Penkowa M, Hidalgo J (2000) Metallothionein I+II expression and their role in experimental autoimmune encephalomyelitis. Glia 32:247-263.

Penkowa M, Hidalgo J (2001) Metallothionein treatment reduces proinflammatory cytokines IL-6 and TNF-alpha and apoptotic cell death during experimental autoimmune encephalomyelitis (EAE). Exp Neurol 170:1-14.
Penkowa M, Hidalgo J (2003) Treatment with metallothionein prevents demyelination and axonal damage and increases oligodendrocyte precursors and tissue repair during experimental autoimmune encephalomyelitis. J Neurosci Res 72:574-586.

Penkowa M, Carrasco J, Giralt M, Moos T, Hidalgo J (1999) CNS wound healing is severely depressed in metallothionein I- and II-deficient mice. J Neurosci 19:2535-2545.

Penkowa M, Carrasco J, Giralt M, Molinero A, Hernandez J, Campbell IL, Hidalgo J (2000) Altered central nervous system cytokine-growth factor expression profiles and angiogenesis in metallothionein-I + II deficient mice. J Cereb Blood Flow Metab 20:1174-1189.

Penkowa M, Giralt M, Thomsen PS, Carrasco J, Hidalgo J (2001) Zinc or copper deficiency-induced impaired inflammatory response to brain trauma may be caused by the concomitant metallothionein changes. J Neurotrauma 18:447-463.

Ricaurte GA, Martello AL, Katz JL, Martello MB (1992) Lasting effects of ( \pm )3,4-methylenedioxymethamphetamine (MDMA) on central serotonergic neurons in nonhuman primates: neurochemical observations. J Pharmacol Exp Ther 261:616-622.

Rojas P, Klaassen CD (1999) Metallothionein-I and -II knock-out mice are not more sensitive than control mice to 1-methyl-4-phenyl-1,2,3,6tetrahydropyridine neurotoxicity. Neurosci Lett 273:113-116.

Rojas P, Rios C (1997) Metallothionein inducers protect against 1-methyl4-phenyl-1,2,3,6-tetrahydropyridine neurotoxicity in mice. Neurochem Res 22:17-22.

Schmidt CJ (1987) Neurotoxicity of the psychedelic amphetamine, methylenedioxymethamphetamine. J Pharmacol Exp Ther 240:1-7.

Tanaka TS, Jaradat SA, Lim MK, Kargul GJ, Wang X, Grahovac MJ, Pantano S, Sano Y, Piao Y, Nagaraja R, Doi H, Wood III WH, Becker KG, Ko MS (2000) Genome-wide expression profiling of mid-gestation placenta and embryo using a 15,000 mouse developmental cDNA microarray. Proc Natl Acad Sci USA 97:9127-9132.

Vawter MP, Barrett T, Cheadle C, Sokolov BP, Wood WH, Donovan D, Webster M, Freed WJ, Becker KG (2001) Application of cDNA microarrays to examine gene expression differences in schizophrenia. Brain Res Bull 55:641-650.

Wijsman JA, Shivers RR (1993) Heat stress affects blood-brain barrier permeability to horseradish peroxidase in mice. Acta Neuropathol 86:49-54.

Xie T, Tong L, Barrett T, Yuan J, Hatzidimitriou G, McCann UD, Becker KG, Donovan DM, Ricaurte GA (2002) Changes in gene expression linked to methamphetamine-induced dopaminergic neurotoxicity. J Neurosci 22: 274-283. 